\title{
Deforestation, Climate Change and Food Security Nexus in Sub- Sahara Africa: Content Analysis
}

Dastan Bamwesigye $^{1^{*} \text {, Petra Hlavackova }}{ }^{1}$, Samuel Antwi Darkwah ${ }^{2}$ and Nahanga Verter ${ }^{2}$ ${ }^{1}$ Department of Forest and Wood Products Economics and Policy, Faculty of Forestry and Wood Technology

${ }^{2}$ Faculty of Regional Development and International Studies

Mendel University in Brno, Zemědělská 1, 61300 Brno, Czech Republic. xbamwesi@mendelu.cz petra.hlavackova@mendelu.cz darkwah@mendelu.cz nahanga.verter@mendelu.cz

* Correspondence: bamwesigyedastan @ gmail.com; Tel.: +420 776332898

Abstract: Like the rest of the globe, Forests in Sub-Saharan Africa (SSA) continue to play a vital role when it comes to food security from the perspective of forest function of climate regulation, water provision, and soil protection. Nevertheless, most of the recent deforestation practices in various countries indicate that the region could face severe food insecurity in the near future since there are already signs of shortage in food production. This study, therefore, examines deforestation, climate change, and food security nexus in SSA while exploring a wide range of examples of food insecurity in the region. Content analysis and a synthetic literature study were conducted using data from scientific data banks. The study links deforestation, climate change to food security while citing examples from various SSA countries such as Cameroon, Nigeria, Kenya to mention but a few. More so, the study investigates how deforestation contributes to climate change, and how such change directly affects agricultural output and hence food security. Lastly, the study discusses the various implication of deforestation in relation to food security.

Keyword: Access, availability, climate change, deforestation, drought, food security, SSA 


\section{Introduction}

Forests play a critical role as key indicators envisaging the state of food security in a range of SubSaharan Africa (SSA) countries. Food insecurity expresses the inability to regularly provide nutritious dependable sources of cheap yet adequately balanced meals. Consequently, the resulting implication of food insecurity is chronic hunger and poor nutrition, which ultimately factors for unhealthy and unproductive populations. This is a significant ongoing problem in SSA. According to [27], with an estimated 239 million people suffering from hunger, an estimate that has significantly soared since. Various researchers [13] observed that Ghana's deforestation rate of $2 \%$ per year, markedly stands as one of the highest in Africa. They projected a complete loss of Ghana's independent remnant forests by 2025 , following impending pressures from deforestation [6]. However, this said, this study [14] deliberately stressed the value of forests as a reliable food insecurity source being the most productive yet easily accessible resources available to rural Cameroonians.

Deforestation, which is coined by the destruction of forest cover to avail land purposely for nonforest use, primarily for agriculture is an immediate trend in SSA countries. More so, in most of SSA, the popularized practice deriving from deforestation is subsistence agriculture with an annual deforestation rate of $0.7 \%$ [30]. More studies [13-14] indicate that Africa Total natural forest cover in SSA declined by $9.5 \%$ between 2000 and 2010, of which over $75 \%$ was converted into agricultural farmland. A wide range of scholars [17-26] observed that nowhere is this nexus of land clearing and degradation with hunger more pronounced than in SSA regions.

Similarly, according to this study [24], many deforestation hotspots are also common hunger zones, thus therefore glaringly implicating deforestation as an issue threatening food security. Entirely, this can be related to the fact that forests offer habitats to a variety of shrub, animal and fish species commonly consumed by forest communities. As revealed in this study [14], foods 
from SSA forests constitute an important component of the household food supply, a food security source deliberately insecure consequent to deforestation [6]. Furthermore, forests provide an essential lifeline towards food security for numerous SSA villages through readily availing some important dietary elements insufficiently supplied by agriculture [28]. To elaborate, local communities in Cameroon consumed mushrooms, Cameroonian ndole, and baobab whilst a variety of tree leaves formed ingredients for local beverages, entirely collected from forests [14]. Therefore, forests offer a strong lifeline toward food security for these communities, assurance deforestation puts at risk.

The paper goes into great lengths of studying the complex relationship between deforestation, climate and food security in SSA herein referred to as a nexus. Consequently, higher deforestation rates proceed doubtful food security implications with deforestation hotspots being common hunger zones [33]. Undoubtedly, forests are valuable and reliable food security sources for SSA countries as habitats for a variety of shrub, animal and fish species commonly consumed by rural communities. Furthermore, poverty-stricken households in this region are heavily reliant on forest products consumption constrained by deforestation [28]. Similarly, deforestation limits access to fuelwood which is vital energy for meal preparation without which many people opt out from meals threatening food security. Ultimately, deforestation an underlying climate change factor resulting in extremities such as drought and floods hampering food availability, access and affordability thus implicating food security [28]. Finally, therefore, SSA countries have adopted remedial measures to curb deforestation in a bid to safeguard food security.

The investigation used content analysis and Literature review approach. This is well-thought-out to be one of the compound research method practice that aims at using, analyzing and coding numerous words of textual data thus attaining valid duplicated inferences [38]. In this research 
study, content analysis was used as a methodology to understand message content as the basis from which implications and conclusions about Deforestation, Climate Change, and Agriculture Production Nexus research are drawn. Additionally, this technique has its uniqueness in confirming authorship, and this usually allows one to determine authorship through correlating the frequencies of nouns or function words following thorough examination of prior writings by the disagreeing authors $[37,38]$.

\section{Deforestation, Climate Change, and Agriculture Production Nexus concept}

The term Nexus is considered to be a Latin word that describes the act of putting together something that binds $[10,18]$. In the case, the nexus approach is used to examine connections, interrelatedness as well as interdependencies of various components as far as the environment is concerned [18]. Concerning deforestation, climate change, and agriculture production, the nexus approach is used to investigate the complex system that influences the environment rather than looking at single components.

Like never before, forests play a significant role in storing large amounts of carbon dioxide [4, 36]. In most cases, when deforestation happens, a large amount of carbon dioxide stored is released back into the atmosphere, and this usually contributes to the plants development process of growth. The existence of forests increases agricultural output since forests protect crops against many elements that could damage [4, 36]. For example, some studies indicate that forests assist in revitalizing soil nutrients, reducing soil erosion, and mitigating climate change [4-6]. Much as the existence of forests contribute to agricultural production; it is worth mentioning that the expansion of agriculture has recently become one of the leading factors of deforestation [5]. As a result, this 
is contributing to climate change that eventually affects the overall agriculture production. Therefore, these three components are linked as far as environment is concerned.

Deforestation is connected with increased atmospheric carbon dioxide, and this usually causes alterations to the surface energy, which leads to both local and international climate change [5, 11]. Currently, population increase across the globe and Africa, in particular, is driving deforestation practices since population growth is linked with the expansion of agricultural lands [20]. Deforestation is expected to increase the demand for agricultural products, and this necessitates clearing huge land for farming. However, research indicates that in most deforested areas, the temperature usually increases, and this threatens agriculture and other forest ecosystem services [20-21]. In other words, forests help capture greenhouse gases such as carbon dioxide, which prevents global warming [11, 12, and 31]. When forests are cleared (deforestation) to expand agricultural activities, this creates further emissions [11]. Studies show that deforestation contributes more than $10 \%$ of carbon dioxide emissions that are driven by human activities.

Currently, scientists and policymakers are working hard to protect forestlands in a bid to tack dangerous climate change. For example, collective policies such as Reducing Emission from Deforestation and Degradation (REDD+) provide incentives for countries that are committed to protect or conserve forests to sustain ecosystem services. In this case, therefore, agriculture production and climate change, which can be achieved through reduced deforestation are linked in one way or the other [1]. Much as reducing deforestation that is caused by agricultural activities seem to be the core objective of various countries and policymakers, demand for food for the evergrowing population continues to push people to the edge to clear more land for farming. However, other investigations revealed that intensification of agriculture production has the potential of reducing pressure for agricultural expansion, especially in most active deforestation frontiers [2]. 
On the other hand, it is indicated that the intensification of agriculture production can as well inspire higher livestock farming and the use of chemical inputs, which has the potential to increase greenhouse gases. As a result, this can as well contribute to climate change, which affects agricultural production in general [2]. In this perspective, climate change across the globe is linked or related to land use and human activities such as deforestation or agriculture. At this point, the core approach or opportunity to mitigate climate change requires policymakers to regulate human activities in a bid to mitigate climate change. A wide range of research shows that deforestation and agriculture affect climate change in various ways [1, 34, 35, and 36]. For example, deforestation leads to changes in average temperatures, rainfall and at the same time soil erosion [35]. At this point, there is no doubt that forests are crucial in mitigating climate change through forest ecosystem services, and this usually improved agriculture production.

As most research investigations paint, deforestation, climate change, and agriculture production seem to go hand in hand [12]. For example, an increase in demand for agricultural products usually hasten the level of deforestation. It is not surprising that agriculture is cited to be one of the leading causes of emissions [2]. Climate change happens not only due to forest cutting in the process of clearing more land for farming, but emissions also come in the form of methane, which is cattle belching as well as nitrous oxide that usually comes from fertilizers and other related elements. More so, research indicates that producing food or agriculture production contributes to climate change due to the increase in emission levels from deforestation and farming practices [16]. Due to animal agriculture/farming, there is always an increase in methane, which is considered to be one of the powerful greenhouse gasses from livestock. On the same note other fertilizers used in farming as agricultural inputs also contribute to global warming; thus, affects climate change [16, 31]. 
In other words, agriculture is becoming one of the core drivers of climate change globally, but most especially in African countries [2, 25]. Emissions resulting from deforestation and other farming practices are heavily contributing to climate change. Like never before, efforts focused on reducing deforestation in developing countries are being undertaken such as REDD+ [15]. At the same time, more effort to reduce hunger while ensuring food security without compromising ecosystem that leads to climate change are also underway, especially through sustainable development goals [25]. In this case, therefore, the assumption is that reducing deforestation and practicing sustainable agricultural practices is the best approach to mitigate climate change $[1,6]$. In most developing countries, there are emerging agricultural practices that are tailored to reconcile food production with the existence of forests. For example, agroforestry is considered to be one of the practices that focus on integrating trees into agriculture. The assumption is that this practice can serve various functions including ecological services as well as agriculture production. At the same time, this can help mitigate climate change in one way or the other.

In a bid to reduce the level of global warming due to deforestation and agriculture production, various ways can be practiced to mitigate climate change [12, 31]. For example, research shows that the agriculture sector has the potential to contribute to climate change mitigation, which can be done through the reduction of greenhouse gas emissions while enhancing agricultural sequestration [7]. For example, it is indicated that the global adoption of organic agriculture can sequester more than $32 \%$ of all human-made greenhouse gas emissions [7, 34]. Organic agriculture is considered to be one of the systems that are used to sustain the health of soils, ecosystems as well as people's health. On the other hand, it is worth mentioning that REDD+, which is also considered as an approach focused on reducing emissions from deforestation, it has great potential to mitigate climate change [7-8]. However, experts suggest that focusing on an area that can 
efficiently reduce emissions can help in ensuring a sustainable environment [15]. Therefore, it can be concluded that deforestation, climate change as well as agriculture production are interconnected in one way or the other [15]. At this point, finding possible solutions to achieve sustainable environment requires an investigation of all components rather than looking at a single aspect.

\section{Extensive Literature Review}

According to [32], SSA countries constitute over 1.02 billion undernourished people proceeded by an alarming 200 million more regrettably facing food insecurity. Further studies [24] indicate that poverty is also a common trend for deforested zones, such as the Democratic Republic of Congo. Its relevance as a statistic to this research is true from the fact that poorer households tend to have a higher reliance on forest products as sources of food security, which is threatened due to deforestation. More studies [14] shows foods collected from forests are smoked, dried or fermented, and kept for extended periods, such as agricultural failure. Thus forest foods offer an important contribution to food security. Therefore, the impending threat of deforestation, however, diminishes the contributive capacity of forests toward food security in SSA for over 300 million people heavily reliant on forests as the primary food security source [19]. Ultimately, it was concluded that continued deforestation poses a severe threat to household food security through constraining consumption of forest food resources for rural populations in Cameroon [14].

Interestingly, merging food security into energy debates similarly offers interesting discussions. Researchers [30] stressed the fact that food requires to be properly cooked before it is safe and palatable for human consumption, thus, therefore, deforestation presents a lack thereof energy conflicting the guarantee of food security. Ultimately, this is evident for SSA, where a quarter of the population is undernourished, mainly resulting from the limited supply of energy [30]. Evidently, over three-quarters of SSA populations lack immediate access to modern energy 
sources, opting for readily available biomass options. Thus, therefore, heavy pressure is applied to biomass fuels for cooking and heating as notable from [30]. Similarly, this pressure possibly results in resource overuse and abuse creating a severe issue for forests that can potentially mature into deforestation, which as previously stressed is detrimental to food security.

As stressed above, a majority of SSA countries rely on biomass energy, this, however, resulting from Deforestation, is also at risk, evident from prolonged fuelwood collection times. This is parallel to [3] that highlighted that lack or limited access to energy reciprocates a lack of food security. In practice, this is resultant of fuelwood scarcity negatively affecting cooking times, leading to long-term adoption of poor dietary habits. The study further stresses that a majority of staple nutrient based principal SSA food crops such as beans are only consumable following proper energy reliant cooking methods. Consequently, fuelwood scarcity pushes many to opt from consuming such foods resulting in nutritionally deprived quality meals negatively affecting food security. Thus, therefore, fuelwood scarcity consequent to deforestation poses challenges to SSA through negatively influencing dietary regimes of people.

Around 13 million hectares of forests are annually lost to various forms of deforestation, resulting in major food security consequences for SSA countries through the resulting climate change [19]. Consequently, deforestation is a significant factor in promoting the ongoing global climate change crisis which leads to increased emission of greenhouse gases, thus altering worldwide temperature and weather patterns. Agriculture, being heavily rain-fed, is highly sensitive to climate change. In this study [13], it was observed that in Ethiopia climate change resulting in extremities such as floods, heat waves, and prolonged drought increased food insecurity in the country. Future climate change projections suggest a global increase in mean temperatures and weather variability by 2050, with repercussions on international agricultural production [29]. Similarly, a study [22] on 
Cameroon's agriculture observed a $46.7 \%$ loss to agricultural output following an increase to temperature and precipitation of $3.5 \%$ and $4.5 \%$ respectively resulting from climate change. This would be detrimental to SSA food security.

Further implications of deforestation on food security for SSA as noted by various scholars [2, 9, $13,27]$ is the cause and effect of climate change on the four key dimensions of food security. Accordingly, climate change affects availability, access to and affordability of food [2]. Consequently, climate change directly affects crops yields a trend adversely reflected in the availability of food products. Owing to deforestation, soil fertility and water holding integrity is compromised resulting from exposure to direct sunlight thus loosening it and exposing it to soil erosion agents [2]. Furthermore, studies [9] indicate that resulting from unstable weather conditions; crop yields seem to fluctuate annually limiting food accessibility in SSA. Irrevocably, in the region, most of the food available to communities is acquired through trade and purchase and rather not supplied by individual households. Severe climatic conditions such as drought affect the availability of seasonal crops, extremes, which therefore prompt market price inflation thus making such foods unaffordable for many [33]. The subsequent implication on food security is that those missing out on such foods involuntarily miss out on the key nutritional value that could have been obtained following consumption of the now unaffordable foods. To elaborate, as a consequence of the severe drought in Kenya [27] observed a sharp spike in the price of staple food the population. The resulting price inflation throughout three months was a rise in rice prices from 60 to 80 shillings per kilogram similarly proceeded by a doubled price of sugar eliminating many people from consuming the given products. Therefore, climate change resulting from deforestation breeds lowered food availability, access and affordability thus, therefore, implicating food security [33]. 
Following these linking implications between deforestation and food security, some SSA countries have endeavored to curb the ongoing issue of deforestation to safeguard food security. More so, it was also revealed that commitments dressing deforestation adhered to include membership to the New York Declaration on Forests as signatories while over 19 SSA actively participate in REDD+ initiatives [13]. Similarly, Nigeria's Cross River State committed to the elimination of deforestation in their territories by 2030. Furthermore, [23, 27] proposed another solution to deforestation purposely stemming from the need for agricultural land in agricultural intensification. In a way, through careful application of fertilizers, with the underlying intention of increasing crops yield thus deterring farmers from engaging in deforestation. As such, all hope is not lost for SSA provided a meditative solution are actively set into place to help curb the impending threat deforestation poses toward food security.

\section{Discussion}

The study extensively implicates deforestation as an important factor affecting food security. Therefore, it is imperative for one to have firsthand information on the linkages between deforestation and food security in SSA. In this case [27], purposely reveals that food security has a negative relationship with deforestation. In fact, with over 239 million people in SSA threatened by food hunger and forests existing as readily accessible food security sources, deforestation is, therefore, a critical problem. Food security is not limited to adequate and reliable food supply but also demands food be of nutritional value; nutrients possibly supplement by forest foods. Admittedly, in SSA, forests assure food security through foods and watershed protection thus avails reliable food supply sources [19]. Admittedly, this is a critical element of SSA food supply similar to studies [14] deliberately indicated the value of forests as a reliable food security source. Therefore, given such glaring implications, one would assume that SSA nations would hold forest preservation in high regard through purposeful reverence to conservation measures. 
However, this is not the case with deforestation vigorously emanating as an impending threat to food security. Therefore, resulting from unsustainable resource use and various socio-economic pressures resulting in high depletion rates, forests are continually stripped of their core value toward food security in SSA. To elaborate, this study [13] revealed a flagrant decline of forest cover in SSA by $9.5 \%$ between 2000 and 2010. Furthermore, around 13 million hectares of forests are annually lost to various forms of deforestation in SSA. Admittedly, these impeding statistics reveal that deforestation does not do justice to the immediate value forests play in ensuring food security in SSA, thus the major problem of the study. To stress, this predicament [26] observed that nowhere is the deforestation and hunger interconnection more pronounced than in SSA. Similarly, [24] points at deforestation hotspots as common hunger zones, further defining the problem of deforestation as a threat toward food security.

To thoroughly understand the vulnerability of food security faces resulting from deforestation, meticulous cross-referencing of relevant studies provided eye-opening information on the extent and the degree to which food security suffers — a few stands out studies which aided in the formulation of the underlying core of the current research. More so, research [14] indicate that rural Cameroonians deliberately relied on forests as a food security source with regards to their productivity and ease with which food resources were accessible to people. This, therefore, stresses in great detail the critical value of forests and the impeding threat therefore that deforestation poses toward food security of rural Cameroonians. Entirely, this is attributed to the fact that forests occur as habitats to a variety of shrub, animal and fish species which are primary food sources for forest communities. Furthermore, the value of forest foods as important constituents of food security is seriously compromised by deforestation. 
To elaborate, studies [13] revealed that local communities in Cameroon consumed mushrooms, Cameroonian ndole, and baobab whilst a variety of tree leaves formed ingredients for local beverages, entirely collected from forests. In effect, therefore, it is confirmed forests avail some essential dietary supplements which for some SSA communities is insufficiently supplied by agriculture. For example, this study [13] shows that foods collected from forests are smoked, dried or fermented, and kept for extended periods, such as agricultural failure. Thus forest foods offer an essential contribution towards food security. Therefore, this affirms the underlying problem that is deforestation through stressing how it undermines the essential lifeline provided by forests towards SSA food security.

Deforestation directly links to food security through the resulting implications the former has on biomass supply in SSA. It can easily be noted that one of the underlying threats deforestation poses to food security in SSA, is fuelwood scarcity resulting from the lack of immediate access to modern energy sources, over three-quarters of SSA populations heavily rely on fuelwood. In effect, therefore, deforestation ultimately deems fuelwood supply insufficient although it is critical in food preparation. Furthermore, for example [30], stressed that a majority of staple SSA foods require thorough cooking for safe and palatable human consumption. Thus, fuelwood scarcity consequent to deforestation poses challenges to SSA food security through imposing fuelwood scarcity.

The study [3] comparably addressed the implications deforestation posed toward food security through prolonged fuelwood collection times. This study similarly expounds on deforestation and resulting fuelwood scarcity’s negative consequence on cooking times. Popular SSA meals such as beans are highly energy dependent to prepare. In this case, fuelwood scarcity usually prompts many to opt from consuming such, resulting in long-term adoption of poor dietary habits thus 
negatively affecting food security. Hence, studies [3] indicate the linkage between deforestation and food security through concluding that lack or insufficient supply of energy conflicts food security through incapacitating proper meal preparation.

Deforestation is also indirectly linked to food security through its pivotal role played in climate change, a global crisis whose effects are severely felt in SSA thus implicating food security through endangering agriculture. Essentially, climate change prompts increased greenhouse gases emission which in the long run increases worldwide temperatures by about 20 , therefore altering weather patterns [36]. Future climate change projections suggest a global increase in mean temperatures and weather variability by 2050 , with repercussions on international agricultural production. Consequently, SSA agriculture is entirely rainfed, thus highly sensitive to discrepancies brought forth by climate change. To expound, researchers [9] stressed the effect of climate change on food security through hindering availability, access to and affordability of food. In effect, weather extremities negatively impact crop yields impeding the availability of food and change of seasons minimizes access to seasonal crops.

Therefore, these effects influence markets prompting market price inflation thus making food unaffordable for many. The subsequent implication on food security is that those missing out on such foods involuntarily miss out on the crucial nutritional value that could have been obtained following consumption of the now unaffordable foods. Similarly, studies in Ethiopia noted that climate change bred extremities such as floods, heat waves and prolonged drought which negatively affected food security in the country [13]. Likewise, [27], observed similar trends in Kenya where price spikes on rice and sugar proceeded with lowered consumption rates on given products. In this perspective, deforestation indirectly affects food security by promoting climate change resulting in lowered food availability, access, and affordability for SSA. Convincingly, 
given the implicating linkages, it is evident that deforestation is a major threat to SSA food security.

\section{Conclusions}

Ultimately, food security is a critical global issue, adversely affecting SSA affecting an estimated 239 million people with further implications suggesting increments to this number. This can be attributed to a multiplicity of factors, but deforestation also plays a fundamental role in compromising food security. It is imperative to purposeful comprehend the relationship between deforestation and food security for SSA. Essentially, deforestation has some implications for food security for some SSA states, through direct and indirect consequences. Admittedly, it is quite sarcastic that in SSA, deforestation is primarily steered by availing land for among other reasons, mainly agriculture. One would hope that this would preach positives towards potential mitigation of the impending food security issues affecting these nations. However, amongst the bonuses, subsequent consequences of deforestation glaringly implicate any possible good intentions through further compromising the state food security.

Resulting from deforestation, fuelwood scarcity further affects food security through impeding meal preparation and cooking times. Interestingly, deforestation does not account for the fact that SSA states popularly rely on biomass energy primarily fuelwood for cooking. Essentially, the constrained adoption of modern energy sources develops over-reliance on readily available biomass energy. In other words, deforestation ultimately deems fuelwood supply insufficient even though it is critical in food preparation [34]. Furthermore, the resulting fuelwood scarcity resulting from deforestation proceeds prolonged fuelwood collection times. In effect, therefore, deforestation breeds fuel scarcity and prolonged collection times which results in stress, negatively affect cooking times. This is problematic for SSA people considering most of the staple foods such as beans require thorough cooking before they are safe to be consumed. As such, some people are 
therefore forced out of eating foods requiring high energy resources for preparation resulting from the fuelwood scarcity. As such, deforestation prompts poor dietary habits through incapacitating one's ability to consume ready meals as a result of actuating fuelwood scarcity thus implicating food security.

Deforestation similarly affects food security through aiding climate change which severely affects SSA agricultural regimes. In effect, climate change prompts an increase in worldwide temperatures due to the accumulation of greenhouse gases resulting in erratic weather patterns. This is a major threat to rain-fed agricultural systems, which is the norm for SSA farms. Erratic climatic conditions usually hinder the growth of certain food crops thus implicating availability and access to various nutritional foods, with available foods heavily priced resulting from the food scarcity. Therefore, many people will be financially incapable of meeting inflated market prices thus miss out on the foods and their resulting nutritional values.

Hopefully however, some SSA countries have endeavored to curb the ongoing issue of deforestation to safeguard food security. In effect, most SSA countries are signatories to the internationally acclaimed REDD+ initiatives. Furthermore, as popularly opposed to the continual clearing of forests for agricultural land, agricultural intensification through fertilizer use is heavily promoted to enable farmers to use the same plot of land for prolonged periods. Therefore, some SSA nations actively aim at curbing deforestation through imposing the above-stated remedies thus aiding food security.

Funding: Please add: "This research received no external funding"

Conflicts of Interest: The authors declare no conflict of interest. 


\section{References}

1. Ackerman F, Stanton EA (2013). Climate Impacts on Agriculture: A Challenge to Complacency? Global Development and Environment Institute Working Paper No. 13-01.

2. Bernard, L., Semmler, W., Ackerman, F., \& Stanton, E. A. (2015). Climate Impacts on Agriculture. The Oxford Handbook of the Macroeconomics of Global Warming. doi:10.1093/oxfordhb/9780199856978.013.0024

3. Bogdanski, A. (2012). Integrated food-energy systems for climate-smart agriculture. Agriculture \& Food Security, 1(1), 9. doi:10.1186/2048-7010-1-9

4. Bosetti, V., \& Lubowski, R. (2010). Deforestation and Climate Change. doi: $10.4337 / 9780857937179$

5. Brown, A. (2016). A world without deforestation. Nature Climate Change, 6(6), 541-541. doi:10.1038/nclimate3047

6. Carter, S. (2018). Deforestation and agriculture in the tropics: carbon emissions and options for mitigation. Retrieved from http://library.wur.nl/WebQuery/wurpubs/535687

7. DeFries, R., \& Rosenzweig, C. (2010). Toward a whole-landscape approach for sustainable land use in the tropics. Proceedings of the National Academy of Sciences, 107(46), 1962719632. Retrieved from https://www.ncbi.nlm.nih.gov/pmc/articles/PMC2993334/

8. Dickie, A., Streck, C., Roe, S., Zurek, M., Haupt, F., \& Dolginow, A. (2014). Strategies for mitigating climate change in agriculture. Abridged Report. Retrieved from https://climatefocus.com/sites/default/files/strategies_for_mitigating_climate_change_in_ agriculture.pdf 
9. Edame, Ekpenyong, Fonta, \& EJC. (2011). Climate Change, Food Security and Agricultural Productivity in Africa: Issues and policy directions. International Journal of Humanities and Social Science, 1(21). Retrieved from http://www.ijhssnet.com

10. Endo, A., Burnett, K., Orencio, P., Kumazawa, T., Wada, C., Ishii, A., Taniguchi, M. (2015). Methods of the Water-Energy-Food Nexus. Water, 7(10), 5806-5830. doi:10.3390/w7105806

11. FAO. (2012). Forest Management and Climate Change: A literature review. Forests and Climate Change Working $\quad$ Paper $10 . \quad$ Retrieved from http://www.fao.org/docrep/015/md012e/md012e00.pdf

12. Fasona, M., Adeonipekun, P. A., Agboola, O., Akintuyi, A., Bello, A., Ogundipe, O., Omojola, A. (2018). Drivers of Deforestation and Land-Use Change in Southwest Nigeria. Handbook of Climate Change Resilience, 1-24. doi:10.1007/978-3-319-71025-9_139-1

13. Franks, P., Hou-Jones, X., Firkreyesus, D., Mamuye, S., Sintayehu, M., Danso, E., \& Meshack, C. (2010). Reconciling forest conservation with food production in sub-Saharan Africa. International Institute for Environment Development, 1(1). Retrieved from https://www.iied.org

14. Gbetnkom, D. (2008). Forest Depletion and Food Security of Poor Rural Populations in Africa: Evidence from Cameroon. Journal of African Economies, 18(2), 261-286. doi:10.1093/jae/ejn012

15. Grantham Research Institute on climate change and the environment. (2018). What is the role of deforestation in climate change and how can 'Reducing Emissions from Deforestation and Degradation' (REDD+) help? Retrieved from 
http://www.lse.ac.uk/GranthamInstitute/faqs/whats-redd-and-will-it-help-tackle-climatechange/

16. Hoffmann, U (2013). Section B: Agriculture: a key driver and a major victim of global warming, in Lead Article, in Chapter 1, in Hoffmann 2013, pp: 3-5. Retrieved from https://unctad.org/en/PublicationChapters/ditcted2012d3_ch1_en.pdf

17. Hosonuma, N., Herold, M., De Sy, V., De Fries, R. S., Brockhaus, M., Verchot, L., ... Romijn, E. (2012). An assessment of deforestation and forest degradation drivers in developing countries. Environmental Research Letters, 7(4), 044009. doi:10.1088/1748$9326 / 7 / 4 / 044009$

18. Howarth, C. (2018). Mitigating and Exacerbating Climate Shocks to the Nexus. Resilience to Climate Change, 23-45. doi:10.1007/978-3-319-94691-7_2

19. Lawrence, D., \& Vandecar, K. (2015). Effects of tropical deforestation on climate and agriculture. Nature Climate Change, 5(1), 27-36. doi:10.1038/nclimate2430

20. Longobardi, P., Montenegro, A., Beltrami, H., \& Eby, M. (2016). Deforestation Induced Climate Change: Effects of Spatial Scale. PLOS ONE, 11(4), e0153357. doi:10.1371/journal.pone.0153357

21. Longobardi, P., Montenegro, A., Beltrami, H., \& Eby, M. (2016). Deforestation Induced Climate Change: Effects of Spatial Scale. PLOS ONE, 11(4), e0153357. Retrieved from https://www.ncbi.nlm.nih.gov/pmc/articles/PMC4839769/

22. Molua, E. L., \& Lambi, C. M. (2007). The Economic Impact of Climate Change on Agriculture in Cameroon, Volume 1of 1. Policy Research Working Papers. doi:10.1596/1813-9450-4364 
23. Olanrewaju, R. M., Tilakasiri, S. L., \& Bello, F. B. (2018). Community perception of deforestation and climate change in Ibadan, Nigeria. Journal of the University of Ruhuna, 6(1), 26. doi:10.4038/jur.v6i1.7866

24. Palm, C. A., Smukler, S. M., Sullivan, C. C., Mutuo, P. K., Nyadzi, G. I., \& Walsh, M. G. (2010). Identifying potential synergies and trade-offs for meeting food security and climate change objectives in sub-Saharan Africa. Proceedings of the National Academy of Sciences, 107(46), 19661-19666. doi:10.1073/pnas.0912248107

25. Pereira, L. (2017). Climate Change Impacts on Agriculture across Africa. Oxford Research Encyclopedia of Environmental Science. doi:10.1093/acrefore/9780199389414.013.292

26. Ravallion, M., \& Chen, S. (2007). Absolute Poverty Measures For The Developing World, 1981-2004. Policy Research Working Papers. doi:10.1596/1813-9450-4211

27. Sasson, A. (2012). Food security for Africa: an urgent global challenge. Agriculture \& Food Security, 1(1), 2. doi:10.1186/2048-7010-1-2

28. Scott, C. E., Monks, S. A., Spracklen, D. V., Arnold, S. R., Forster, P. M., Rap, A., ... Wilson, C. (2018). Impact on short-lived climate forcers increases projected warming due to deforestation. Nature Communications, 9(1). doi:10.1038/s41467-017-02412-4

29. Shah, Mahendra, Fisher, \& Velthuizen. (2017). Rainfed agriculture, climate change and food security. A report submitted for discussion at the FAO Expert Meeting on Climate Change, Water and Food Security, FAO, Rome, (1). doi:10.14775/eod_tg.april2015.gristn

30. Sola, P., Ochieng, C., Yila, J., \& Iiyama, M. (2016). Links between energy access and food security in sub Saharan Africa: an exploratory review. Food Security, 8(3), 635-642. doi:10.1007/s12571-016-0570-1 
31. Stoy, P. C. (2018). Deforestation intensifies hot days. Nature Climate Change, 8(5), 366368. doi:10.1038/s41558-018-0153-6

32. [32] Umar, O., \& Ozohu, O. (2015). Impact of Climate Change on Agricultural Production and Food Supply in Africa. International Conference on Latest Trends in Food, Biological \& Ecological Sciences (ICLTFBE'15) Oct. 11-12, 2015 Dubai (UAE). doi:10.17758/iaast.a1015057

33. Upton, J. (2015). Farming Now Worse For Climate than Deforestation. Retrieved from http://www.climatecentral.org/news/farming-now-worse-for-climate-than-deforestation18629

34. Venkateswarlu, B., \& Singh, A. K. (2015). Climate Change Adaptation and Mitigation Strategies in Rainfed Agriculture. Climate Change Modelling, Planning and Policy for Agriculture, 1-11. doi:10.1007/978-81-322-2157-9_1

35. Wolosin, M., \& Harris, N. (2018). Tropical Forests and Climate Change: The Latest Science. Ending Tropical Deforestation: A Stock-Take of Progress and Challenges, 1. Retrieved from https://wriorg.s3.amazonaws.com/s3fs-public/ending-tropicaldeforestation-tropical-forests-climate-change.pdf

36. Yohannes, H. (2015). A Review on Relationship between Climate Change and Agriculture. Journal of Earth Science \& Climatic Change, 07(02). doi:10.4172/2157-7617.1000335.

37. Nachmias, D. \& Nachmias, C. (1976). Content analysis. In Research methods in the social sciences (pp.132-139), UK: Edward Arnold.

38. Elo, S., \& Kyngas, H. (2007). The qualitative content analysis process. Journal of Advanced Nursing, 62(1), 107-115. doi: 10.1111/j.1365-2648.2007.04569.x 